\title{
Alleviating oxidative damage-induced telomere attrition: a potential mechanism for inhibition by folic acid of apoptosis in neural stem cells
}

\section{Zhenshu Li}

Tianjin Medical University

\section{Wen Li}

Tianjin Medical University

Dezheng Zhou

Tianjin Medical University

Jing Zhao

Tianjin Medical University

\section{Yue Ma}

Tianjin Medical University

\section{Ling Huang}

Tianjin Medical University

\section{Cuixia Dong}

Tianjin Medical University

John X. Wilson

University at Buffalo

Guowei Huang ( $\sim$ huangguowei@tmu.edu.cn )

Tianjin Medical University https://orcid.org/0000-0002-0664-403X

\section{Research Article}

Keywords: folic acid, apoptosis, telomere attrition, oxidative damage, neural stem cell, in vitro

Posted Date: August 9th, 2021

DOl: https://doi.org/10.21203/rs.3.rs-182747/v1

License: (c) (i) This work is licensed under a Creative Commons Attribution 4.0 International License. Read Full License

Version of Record: A version of this preprint was published at Molecular Neurobiology on November 5th, 2021. See the published version at https://doi.org/10.1007/s12035-021-02623-3. 


\section{Abstract}

DNA oxidative damage can cause telomere attrition or dysfunction that triggers cell senescence and apoptosis. The hypothesis of this study is that folic acid decreases apoptosis in neural stem cells (NSCs) by preventing oxidative stress-induced telomere attrition. Primary cultures of NSCs were incubated for 9 days with various concentrations of folic acid $(0-40 \mu \mathrm{M})$ and then incubated for $24 \mathrm{~h}$ with a combination of folic acid and an oxidant (100 $\mu \mathrm{M}$ hydrogen peroxide, $\mathrm{H} 2 \mathrm{O} 2)$, antioxidant $(10 \mathrm{mM} \mathrm{N}$ acetyl-L-cysteine, NAC) or vehicle. Intracellular folate concentration, apoptosis rate, cell proliferative capacity, telomere length, telomeric DNA oxidative damage, telomerase activity, intracellular reactive oxygen species (ROS) levels, cellular oxidative damage, and intracellular antioxidant enzyme activities were determined. The results showed that folic acid deficiency in NSCs decreased intracellular folate concentration, cell proliferation, telomere length and telomerase activity, but increased apoptosis, telomeric DNA oxidative damage and intracellular ROS levels. In contrast, folic acid supplementation dose-dependently increased intracellular folate concentration, cell proliferative capacity, telomere length and telomerase activity but decreased apoptosis, telomeric DNA oxidative damage and intracellular ROS levels. Exposure to $\mathrm{H} 2 \mathrm{O} 2$ aggravated telomere attrition and oxidative damage whereas NAC alleviated the latter. High doses of folic acid prevented telomere attrition and telomeric DNA oxidative damage by $\mathrm{H}$ 202 . In conclusion, inhibition of telomeric DNA oxidative damage and telomere attrition in NSCs maybe potential mechanisms of inhibiting NSCs apoptosis by folic acid.

\section{Introduction}

Oxidative damage contributes to neuronal cell death and therefore to the important public health problems of aberrant aging and neurodegenerative disease [1,2]. Neural stem cells (NSCs) are the main cell types that produce central nervous system, which are essential for the study of neural development, neurodegeneration and nervous system diseases [3]. NSC homeostasis is influenced by oxidative damage, when the balance between proliferation and differentiation are destroyed, adult neurogenesis disturbed. NSC oxidative damage, remains in a tight connection with the occurrence of central nervous system diseases [2]. However, the mechanism of oxidative damage the causes neural cell apoptosis remains to be clarified.

Telomeres are repeating hexameric DNA sequences that protect chromosomes from degradation and end-to-end fusion. Epidemiological studies have revealed that loss of telomere integrity is an important factor in the decay of physiological function associated with ageing and several chronic illnesses $[4,5]$. Damage to telomeric sequences in stem cells can be repaired by a specialized reverse transcriptase called telomerase [6]. Telomere state depends not only on telomere length but also on the repair that counteracts telomere loss by adding de novo repeats to the $3^{\prime}$ ends [7]. Oxidative stress has been observed to accelerate telomere attrition in primary astrocytes [8] and to be associated with apoptosis in endothelial cells [9]. Nevertheless, the role of oxidative stress, telomere attrition and telomerase activity in neurodegeneration is still unclear. 
Telomere attrition is associated with ageing, genetic and environmental factors such as nutrients $[10,11]$. Folate (vitamin $B_{9}$ ) is an essential nutrient that acts as a coenzyme to transfer the one-carbon units that are necessary for deoxythymidylate synthesis, purine synthesis, and many methylation reactions [12]. Folic acid has been observed to stimulate the proliferation and neuronal differentiation of NSCs, as well as to decrease their apoptosis $[13,14]$. Folic acid deficiency has been found to increase reactive oxygen species (ROS) levels and DNA damage in the context of cancer $[15,16]$, while folic acid supplementation inhibits oxidative stress-induced damage, telomere attrition and apoptosis both in primary astrocytes and a murine model of neurodegenerative disease $[8,17]$. However, the relationship between folate, telomerase activity and telomere attrition in NSCs is still unknown. The hypothesis of this study is that folic acid decreases apoptosis in NSCs by preventing oxidative stress-induced telomere attrition.

\section{Materials And Methods}

\section{Cell Culture}

The Tianjin Medical University Animal Ethics Committee approved all experimental protocols in this study. Hippocampus and striatum were dissected from neonatal (postnatal less than 24 hours) SpragueDawley rats (Charles River Laboratories, Beijing, China) and NSCs were prepared as described previously [12]. Hippocampus and striatum tissues were cut into $1 \mathrm{~mm}^{3}$ pieces and digested with $0.25 \%$ trypsin at $37^{\circ} \mathrm{C}$ for $15 \mathrm{~min}$. This step was followed by agitation, centrifugation and resuspension of the cells in serum free Dulbecco's modified Eagle's medium (DMEM) and nutrient mixture F-12 Ham (F12) (1:1) (Corning, NY, USA), supplemented with $2 \%$ B27 supplement (Gibco, USA), $20 \mathrm{ng} / \mathrm{mL}$ epidermal growth factor (EGF; PeproTech, USA), $20 \mathrm{ng} / \mathrm{mL}$ basic fibroblast growth factor (bFGF; PeproTech), $100 \mathrm{U} / \mathrm{mL}$ penicillin and phytomycin (Slarbio) and $2 \mathrm{mmol} / \mathrm{L} \mathrm{L-glutamine} \mathrm{(Sigma,} \mathrm{USA).} \mathrm{The} \mathrm{resulting} \mathrm{cell}$ suspension was plated at $1 \times 10^{6}$ cells/mL in T25 culture flasks (Corning, NY, USA), then cultured in 95\% air and $5 \% \mathrm{CO} 2$ at $37{ }^{\circ} \mathrm{C}$, and the culture medium was changed every 2 or 3 days. After purification ( 7 days), NSCs were incubated for 9 days with various concentrations of folic acid (0-40 $\mu \mathrm{M})$. Then the cells were exposed for $24 \mathrm{~h}$ to medium containing a combination of folic acid and either oxidant $(100 \mu \mathrm{M}$ hydrogen peroxide, $\mathrm{H}_{2} \mathrm{O}_{2}$ ) or antioxidant (10 mM N-acetyl-L-cysteine, NAC) or vehicle. The dosage ranges of $\mathrm{H}_{2} \mathrm{O}_{2}$ and NAC were selected according to data from the literature $[18,19]$ and the results of our preliminary experiments. After subjected to the different study conditions for 10 days, cells were harvested to detect intracellular folate concentration, apoptosis, cell viability, ROS and oxidative damage, antioxidant activities and telomere attrition.

\section{Cell Identification}

By the end of 7 days in culture, NSC neurospheres were gently mechanically dissociated and plated on laminin $(100 \mu \mathrm{g} / \mathrm{mL})$ coated coverslips, incubated with $1 \mathrm{mM}$ 5-bromo-20-deoxyuridine (BrdU, Sigma, USA) in proliferative medium for $24 \mathrm{~h}$, then fixed with $4 \%$ paraformaldehyde for $20 \mathrm{~min}$ at room temperature. The cells were washed with phosphate-buffered saline (PBS), permeabilized with $0.1 \%$ Triton X-100 for 15 min at room temperature, blocked with $10 \%$ goat serum for $1 \mathrm{~h}$ at $37^{\circ} \mathrm{C}$, and 
incubated with primary antibodies (mouse anti-BrdU antibody [1:50, Sigma, USA]; rabbit anti-SOX2 antibody [1:200, Abcam, UK] overnight at $4{ }^{\circ} \mathrm{C}$. After another washing with PBS, the coverslips were incubated with secondary antibodies (tetramethyl rhodamine isothiocyanate [TRITC]-conjugated antimouse antibody, 1:100; fluorescein isothiocyanate-conjugated antirabbit antibody, 1:100, Jackson, USA) for $1 \mathrm{~h}$ at room temperature and counterstained with 4',6-diamidino-2-phenylindole (DAPI) contained Vectashield (H1200, Vector). The potential capacity of cultured NSC was assessed by immunocytochemistry. NSC neurospheres were gently mechanically dissociated and the resulting cells were plated on laminin $(100 \mu \mathrm{g} / \mathrm{mL})$ coated coverslips at a density of $2 \times 10^{4}$ cells $/ \mathrm{mL}$ in DMEM/F12 medium supplemented with $5 \%$ fetal bovine serum (FBS; Gibco), 2\% N2 (Gibco) and $100 \mathrm{U} / \mathrm{mL}$ penicillin and phytomycin (Gibco), but without B27, EGF, or bFGF [12]. After 6 days of differentiation, the cells were fixed with $4 \%$ paraformaldehyde for $20 \mathrm{~min}$ at room temperature. After washing with PBS, the cells were blocked with $10 \%$ goat serum for $1 \mathrm{~h}$ at $37^{\circ} \mathrm{C}$, and incubated with primary antibodies (mouse anti- $\beta-1 \mathrm{II}-$ Tubulin antibody [1:1000, Abcam]; rabbit anti-glial fibrillary acidic protein (GFAP) antibody [1:1000, Abcam]) overnight at $4{ }^{\circ} \mathrm{C}$. After another washing with PBS, the coverslips were incubated with secondary antibodies (tetramethyl rhodamine isothiocyanate [TRITC]-conjugated goat anti-mouse antibody, 1:100; fluorescein isothiocyanate-conjugated goat anti-rabbit antibody, 1:100, Jackson, USA) for $1 \mathrm{~h}$ at room temperature and counterstained with DAPI contained Vectashield (H1200, Vector). Immunofluorescence signals were captured using Olympus IX81 microscope (Olympus) and analyzed by Image-Pro Plus 6.0 software.

\section{Intracellular Folate Assay}

An aliquot of $10^{7}$ cells was centrifuged, suspended in phosphate-buffered saline (PBS), sonicated twice for 10 seconds each time, then centrifuged at $5000 \times g$ for $5 \mathrm{~min}$ and the resulting supernatant was collected to detect folate content. Folate was measured using a competitive protein-binding assay (IMMULITE® 2000 Folic Acid kit) with an automated chemiluminescence immunoassay analyzer (IMMULITE 2000 XPi, Siemens Healthcare Diagnostics Inc., Malvern, PA, USA) according to the manufacturer's specifications. This assay was able to detect folic acid, dihydrofolate, and tetrahydrofolate from 1-24 ng/mL. Folate levels in cells were normalized by protein content, as determined by the BCA Protein Assay Kit (Boster, Wuhan, China).

\section{Cell Apoptosis Assay}

Cell apoptosis was measured by The DeadEnd ${ }^{\text {TM }}$ Fluorometric TUNEL System (G2350, Promega, America). This terminal deoxynucleotidyl transferase (TdT)-mediated deoxyuridine monophosphate (dUTP) nick end labeling (TUNEL) assay detects nuclear DNA fragmentation, which is a hallmark of apoptosis. Briefly, NSCs on coverslips were fixed in $4 \%$ paraformaldehyde for $25 \mathrm{~min}$, washed twice with PBS, permeabilized with $0.2 \%$ Triton X-100 for $5 \mathrm{~min}$ and then incubated in the dark with Equilibration Buffer for $10 \mathrm{~min}$ at room temperature. rTdT incubation buffer was added for $60 \mathrm{~min}$ at $37^{\circ} \mathrm{C}$. Then terminate the reactions by $2 \times$ SSC for 15 min at room temperature. Finally, the cells were incubated with DAPI, washed twice with PBS, and mounted with a fluorescent mounting medium. We detected localized green fluorescence of 
apoptotic cells (fluorescein-12-dUTP) in a blue background (DAPI) by a fluorescence microscope (Olympus, Tokyo, Japan). Positive cells were counted using Image Pro Plus 6.0 software.

\section{Cell Proliferation Assay}

NSC proliferation was measured by BrdU incorporation [20]. Briefly, NSCs on coverslips were incubated with $10 \mu \mathrm{M}$ BrdU (Sigma, USA) in proliferative medium for $24 \mathrm{~h}$, then fixed in $4 \%$ paraformaldehyde for 20 min at room temperature. The cells were washed twice with PBS, permeabilized with $0.1 \%$ Triton X-100 for $15 \mathrm{~min}$ at room temperature, blocked with $10 \%$ goat serum for $1 \mathrm{~h}$ at $37^{\circ} \mathrm{C}$, and incubated with primary mouse anti-BrdU antibody $\left(1: 100\right.$, Sigma) overnight at $4{ }^{\circ} \mathrm{C}$. After another washing with PBS, the coverslips were incubated with secondary TRITC-conjugated goat anti-mouse antibody (1:100, Proteintech) for $1 \mathrm{~h}$ at room temperature and counterstained with DAPI contained Vectashield (H1200, Vector). Immunofluorescence signals were captured using Olympus IX81 microscope (Olympus) and analyzed by Image-Pro Plus 6.0 software.

\section{Cell Viability Assay}

Cell viability was measured with the CellTiter $96 \AA$ AQueous One Solution Cell Proliferation Assay (Promega Corporation, Madison, WI, USA) that uses 3-(4,5-dimethylthiazol-2-yl)-5-(3-

carboxymethoxyphenyl)-2-(4-sulfophenyl)-2H-tetrazolium (MTS). Cells were seeded into a 96-well plate at a density of $1 \times 10^{4}$ cells per well $(200 \mu \mathrm{L} /$ well). Then $20 \mu \mathrm{L}$ of MTS $(5 \mathrm{mg} / \mathrm{mL})$ was added to each well, and the mixture was incubated at $37{ }^{\circ} \mathrm{C}$ for an additional $3 \mathrm{~h}$ in a humidified, $5 \% \mathrm{CO}_{2}$ atmosphere. The absorbance at $490 \mathrm{~nm}$ was recorded using a microplate reader (ELX800uv ${ }^{\mathrm{TM}}$; BioTek Instruments Inc).

\section{Measurement of Telomere Length by Southern Blot}

The telomere restriction fragment (TRF) analysis was performed using a commercial kit (TeloTAGGG Telomere Length Assay, Roche Life Science, Mannheim, Switzerland), based on the instruction. Briefly, 150ng genomic DNA sample was digested with Hinf I and Rsa I for $2 \mathrm{~h}$ at $37^{\circ} \mathrm{C}$. Digested DNA was then electrophoresed on $1 \%$ agarose pulsed field gels at $6 \mathrm{~V} / \mathrm{cm}$ for $11 \mathrm{~h}$. The blotting membrane was washed, blocked, incubated with anti-DIG-alkaline phosphatase (1:4000 dilution, Roche, Mannheim, Switzerland) for $4 \mathrm{~h}$, washed, and exposed with CDP-star (Roche, Mannheim, Switzerland) for $15 \mathrm{~min}$. After exposure of the blot to an X-ray film, an estimate of the mean TRF length can be obtained by comparing the mean size of the smear to the molecular weight marker with Telo Tool.

\section{Measurement of Telomere Length by qPCR}

Genomic DNA was extracted using the Wizard ${ }^{\circledR}$ Genomic DNA Purification kit (Promega Corporation, Madison, WI, USA) according to the manufacturer's instructions and was quantified with a NanoDrop 2000 instrument (Thermo Scientific, USA). qPCR assay was used to determine telomere length as previously used [21]. We used a PCR mixture of $25 \mu \mathrm{L}$ including $12.5 \mu \mathrm{L}$ of SYBR Green qPCR Supermix (2x), $1 \mu \mathrm{L}$ of DNA, $1 \mu \mathrm{L}$ of 36B4 forward and reverse primers $(10 \mu \mathrm{M})$ or $1 \mu \mathrm{L}$ of telomere forward and 
reverse primers $(10 \mu \mathrm{M})$, and $\mathrm{H}_{2} \mathrm{O}$ (PCR-grade). The PCR process was Stage 1: 5 min at $95^{\circ} \mathrm{C}$; Stage 2: two cycles of $15 \mathrm{~s}$ at $90^{\circ} \mathrm{C}, 15 \mathrm{~s}$ at $49^{\circ} \mathrm{C}$; Stage $3: 40$ cycles of $15 \mathrm{~s}$ at $90^{\circ} \mathrm{C}, 10 \mathrm{~s}$ at $62^{\circ} \mathrm{C}, 15 \mathrm{~s}$ at $74{ }^{\circ} \mathrm{C}$ with signal acquisition. PCR was performed using the reference control gene (36B4 single-copy gene) and the telomeric gene. Primers were specific for telomeric gene (forward, $5^{\prime}$ -

GGTTTTTGAGGGTGAGGGTGAGGGTGAGGGTGAGGGT-3'; reverse, 5'-TCCCGA

CTATCCCTATCCCTATCCCTATCCCTATCCCTA-3') and 36B4 (forward, 5'-

CAGCAAGTGGGAAGGTGTAATCC-3'; reverse, 5'- CCCATTCTATCATCAACGGGTACAA-3') [22]. All qPCR reactions were performed in a LightCycler $480 \mathbb{Q}$ instrument (Roche Applied Science, Switzerland).

\section{Immunofluorescence-Fluorescent In Situ Hybridization (IF-FISH)}

Telomeric DNA oxidative damage was measured using IF-FISH, as described previously [23]. NSCs were fixed with $4 \%$ paraformaldehyde for $25 \mathrm{~min}$, exposed to $0.5 \%$ Triton X-100 for $20 \mathrm{~min}$, Cy3-labeled telomere PNA probe (PNA Bio) hybridization solution was added to the slides. After denaturation $\left(85^{\circ} \mathrm{C}, 5\right.$ min), the slides were left to hybridize overnight at RT in darkness. Next the slides were washed with washing liquor ( $70 \%$ formamide; $1 \mathrm{M}$ Tris- $\mathrm{HCl}, \mathrm{pH}=7.2)$ and thrice with tris buffered saline with Tween. Blocking was done with $10 \%$ goat serum for $1 \mathrm{~h}$, followed by incubation with anti-phosphohistone $\mathrm{H} 2 \mathrm{AX}$ ( $\mathrm{Y}$-H2AX) (Ser139) (1:500, Millipore, MA, USA) for $10 \mathrm{~h}$ at $4{ }^{\circ} \mathrm{C}$ and secondary FITC goat anti-mouse antibody (1:500, SparkJade) for $1 \mathrm{~h}$. Images of cells were acquired using an inverted fluorescence microscope (Olympus). To determine whether 8-hydroxy-2'-deoxyguanosine (8-OHdG) incorporation caused telomere dysfunction, $\mathrm{y}-\mathrm{H} 2 \mathrm{AX}$ was used to mark telomere dysfunction-induced foci (TIFs). The cells were considered TIF-positive if they contained more than two IF foci of both C-rich telomere probeFITC (TeIC-FITC) and the DNA damage response protein Y-H2AX [24].

\section{Measurement of 8-0xoguanine (8-0xoG) in Telomeric DNA by qPCR}

DNA was isolated and quantified as described above. Equivalent amounts of DNA (approximately $20 \mathrm{ng} /$ $\mu \mathrm{L}$ ) were incubated with formamidopyrimidine DNA-glycosylase (FPG) (NEB, USA) or nuclease-free water for $16 \mathrm{~h}$, followed by a telomere-specific PCR assay [25]. FPG cleaved oxidized guanine-containing DNA to create a fragmentary template for the subsequent PCR, and Ct values increased. The reaction mixtures composed of $12.5 \mu \mathrm{L}$ of SYBR Green qPCR Supermix (2x), $1 \mu \mathrm{L}$ of DNA, $1 \mu \mathrm{L}$ of telomere forward and reverse primers $(10 \mu \mathrm{M})$, and PCR-grade water were incubated at $95^{\circ} \mathrm{C}$ for $10 \mathrm{~min}$, followed by 40 amplification cycles (denaturation, $95^{\circ} \mathrm{C}$ for $15 \mathrm{~s}$; annealing and extension, $60^{\circ} \mathrm{C}$ for $1 \mathrm{~min}$ ), and telomere specific primers (forward, 5'-GGTTTTTGAGGGTGAGGGTGAGGGTGAGGGTGAGGGT-3'; reverse, 5'TCCCGA CTATCCCTATCCCTATCCCTATCCCTATCCCTA-3').

\section{Measurement of Telomerase Activity}

Telomerase is a ribonucleic acid-protein complex composed of a single long non-coding RNA, called telomerase RNA, and associated proteins. We used a telomerase activity quantification qPCR assay kit (ScienCell, Carlsbad, CA, USA \#8928) to measure the products of telomerase activity that are amplified by qPCR. The cell lysis buffer enables the release of telomerase in the native state and the telomere primer 
set (TPS) recognizes and amplifies newly synthesized telomere sequences in the assay. Cell proteins were extracted by cell lysis buffer supplemented with PMSF 0.1 M in isopropanol and $\beta$-mercaptoethanol. After cell protein extraction telomerase reaction was performed as described in the product protocol. First, the telomerase reactions (including $0.5 \mu \mathrm{L}$ cell lysate sample, $4 \mu \mathrm{L} 5 \times \mathrm{g}$ telomerase reaction buffer and $15.5 \mu \mathrm{L}$ nuclease-free $\mathrm{H}_{2} \mathrm{O}$ ) were incubated at $37^{\circ} \mathrm{C}$ for $3 \mathrm{~h}$. The reaction was stopped by heating at $85^{\circ} \mathrm{C}$ for $10 \mathrm{~min}$ and the reaction tubes were centrifuged at $1,500 \times g$ for $10 \mathrm{~s}$. Finally, qPCR was performed to analyze the telomer production by telomerase. The qPCR process was $10 \mathrm{~min}$ at $95^{\circ} \mathrm{C}$, followed by 40 cycles (denaturation, $95^{\circ} \mathrm{C}$ for $20 \mathrm{~s}$; annealing, $95^{\circ} \mathrm{C}$ for $20 \mathrm{~s}$ and extension, $72{ }^{\circ} \mathrm{C}$ for $45 \mathrm{~s}$ ).

\section{Intracellular ROS Assay}

Intracellular ROS levels were determined by the chemiluminescence method with 2',7'-dichlorofluorescin diacetate (DCFH-DA; ROS Assay Kit, Nanjing Jiancheng Bioengineering Institute). Briefly, NSCs were incubated with $10 \mu \mathrm{M}$ DCFH-DA for $30 \mathrm{~min}$ in a dark, humidified $5 \% \mathrm{CO}_{2}$ atmosphere. The cells were washed twice with PBS to remove extracellular fluorescence probes, then centrifugated and resuspended in PBS. Fluorescence intensity was quantified by a fluorescence microplate reader (ELX800uv ${ }^{\mathrm{TM}}$; BioTek Instruments Inc) with excitation wavelength at $500 \mathrm{~nm}$ and emission wavelength at $525 \mathrm{~nm}$.

\section{Measurement of Oxidative Damage}

Lactate dehydrogenase (LDH) activity in culture medium, lipid peroxide (LPO) and malondialdehyde (MDA) in cells were assayed using commercial kits (Nanjing Jiancheng Bioengineering Institute, Nanjing, China) according the manufacturer's instructions. The percentage of LDH release was calculated by the equation: $\mathrm{LDH}$ release $(\%)=($ Experimental LDH release - spontaneous $\mathrm{LDH}$ release $) /$ maximum LDH release. Cellular LPO and MDA concentrations were normalized to the cellular protein content, as determined by a BCA protein assay kit (BosterBio).

\section{Antioxidant Activity Assays}

The intracellular total antioxidant capacity (T-AOC), superoxide dismutase (SOD), catalase (CAT), glutathione peroxidase (GSH-PX) and GSH/oxidized glutathione (GSSG) levels were assayed with commercial kits (Nanjing Jiancheng Bioengineering Institute) according to the manufacturer's protocol. Cellular T-AOC, SOD, CAT, GSH-PX activities were normalized to the cellular protein levels, determined using a BCA protein assay kit (BosterBio).

\section{Statistical Analysis}

Data are expressed as mean \pm SEM values based on three independent experiments. Two-way analysis of variance was used to evaluate differences between the treatment groups, and the Student-NewmanKeuls test was used for multiple comparisons to determine significant differences among the experimental groups. Correlations were assessed using the Pearson's method. The statistical software 
package SPSS 24.0 was used to evaluate the differences within groups, and $p$ value less than 0.05 was considered statistically significant.

\section{Results}

\section{Cell Identification}

By the end of 7 days in culture, almost all the NSCs in neurospheres had the potential to proliferate as indicated by incorporation of Brdu (Additional figure 1a) and they also were SOX2-positive (Additional figure $1 \mathrm{~b}$ ). Then the neurospheres were mechanically dissociated and the resulting cells were cultured in DMEM/F12 medium supplemented with $5 \%$ FBS, $2 \%$ N2, but without B27, EGF, or bFGF. After 6 days culture in this differentiation medium, most of the NSCs had differentiated into neurons or astrocytes, which were identified as $\beta$-III-tubulin-positive and GFAP-positive, respectively (Additional figure 1e-h). These results demonstrate that the cultured neurospheres were comprised of NSCs with the capacity for self-renewal as well as for neuronal and astrocytic differentiation.

\section{Intracellular Folate Level}

After 10 days of intervention, folic acid increased the intracellular folate concentration in a dosedependent manner $(F=233.601, p<0.001)$ (Figure 1). In contrast, NAC had no effect on intracellular folate. $\mathrm{H}_{2} \mathrm{O}_{2}$ also had no effect on the intracellular folate when medium contain high level of folic acid. However, when cells were in 0 or $10 \mu \mathrm{M}$ folic acid medium, $\mathrm{H}_{2} \mathrm{O}_{2}$ decreased the intracellular folate concentration $(\mathrm{F}=26.402, p=0.036 ; \mathrm{F}=128.259, p=0.008)$. These data indicate oxidative stress can lower the intracellular folate concentration unless the extracellular supply of the vitamin is high.

\section{(Insert Figure 1 here)}

\section{Folic Acid Decreased Cell Apoptosis}

To investigate the cytoprotective effect of folic acid, cell apoptosis rate was assessed using TUNEL assay. Folic acid decreased the cell apoptosis in NSCs in a dose-dependent manner $(F=71.728, p<0.001)$ (Figure 2). Folic acid also dose-dependently decreased cell apoptosis when the medium contained $\mathrm{H}_{2} \mathrm{O}_{2}$ $(\mathrm{F}=423.244, p=0.002)$ or NAC $(\mathrm{F}=1142.353, p=0.001)$. High folic acid $(40 \mu \mathrm{M})$ decreased cell apoptosis compared with the other three dosages when the medium contained $\mathrm{H}_{2} \mathrm{O}_{2}$. Meanwhile, 20 or $40 \mu \mathrm{M}$ folic acid decreased apoptosis compared with 0 or $10 \mu \mathrm{M}$ folic acid when the medium contained NAC. These data indicated folic acid deficiency increased cell apoptosis, whereas folic acid, especially high level of folic acid could decrease apoptosis of NSCs.

(Insert Figure 2 here)

Folic Acid Increased Cell Proliferative Capacity 
Cell proliferation and cell viability were assessed using BrdU incorporation and MTS, respectively. Folic acid increased cell proliferation in NSCs in a dose-dependent manner ( $F=192.746, p<0.001)$ (Figure 3a-e). Folic acid also dose-dependently increased cell proliferation when the medium contained $\mathrm{H}_{2} \mathrm{O}_{2}$ $(\mathrm{F}=26530.421, p<0.001)$ or NAC $(\mathrm{F}=11580.757, p<0.001)$.

Folic acid dose-dependently increased cell viability in the absence $(\mathrm{F}=59.457, p<0.001)$ and presence of exogenous $\mathrm{H}_{2} \mathrm{O}_{2}(\mathrm{~F}=961.137, p=0.001)$ (Figure 3f). However, in the presence of NAC, only the highest dose of folic acid $(40 \mu \mathrm{M})$ increased cell viability $(\mathrm{F}=4510.192, p<0.001)$.

These results showed that folic acid deficiency decreased NSC proliferation and cell viability, and folic acid supplementation could increase cell proliferative capacity.

\section{(Insert Figure 3 here).}

\section{Folic Acid Inhibited Telomere Shortening}

Southern blot analysis of telomere length revealed that high folic acid $(40 \mu \mathrm{M})$ inhibited telomere shortening compared with the other three folic acid dosages ( $F=5.285, p=0.009)$ (Figure $4 a, b)$. Furthermore, relative telomere length assayed by qPCR was shortened by folic acid deficiency and increased by high folic acid concentrations $(20$ and $40 \mu \mathrm{M})$ in a dose-dependent manner $(F=33.822$, $p<0.001$ ) (Figure 4c). Similar effects of folic acid occurred when the medium contained $\mathrm{H}_{2} \mathrm{O}_{2}$ or NAC (Figure 4c). The results of telomere length indicated folic acid, especially high level of folic acid (40 $\mu \mathrm{M})$ could inhibit telomere attrition of NSCs.

\section{(Insert Figure 4 here).}

\section{Folic Acid Inhibited Telomeric DNA Oxidative Damage}

High folic acid $(40 \mu \mathrm{M})$ decreased the ratio of TIF-positive cells compared with the other three folic acid dosages with or without $\mathrm{H}_{2} \mathrm{O}_{2}(\mathrm{~F}=26.683, p<0.001)$ (Figure $\left.5 \mathrm{a}-\mathrm{e}\right)$. The incorporation ratio of 8-0xoG within telomeric DNA was increased by folic acid deficiency and decreased by folic acid in a dose-dependent manner ( $F=51.7721, p<0.001)$ (Figure 5f). These data showed folic acid, especially high level of folic acid $(40 \mu \mathrm{M})$ could inhibit telomeric DNA oxidative damage of NSCs.

(Insert Figure 5 here).

\section{Folic Acid Increased Telomerase Activity}

The expression of telomerase RNA was too low to detect (defined by the kit manufacturer's instructions as a Cq-value higher than 33) in 3 treatment groups, namely, $0 \mu \mathrm{M}$ folic acid with or without $\mathrm{H}_{2} \mathrm{O}_{2}$, and $10 \mu \mathrm{M}$ folic acid with $\mathrm{H}_{2} \mathrm{O}_{2}$ (Table 1). Folic acid (10-40 $\mu \mathrm{M}$ ) increased the telomerase activity dosedependently $(\mathrm{F}=35.746, p<0.001)$. 
The oxidant $\mathrm{H}_{2} \mathrm{O}_{2}$ decreased the telomerase activity in the NSCs that received 0 and $10 \mu \mathrm{M}$ folic acid (Table 1), whereas the antioxidant NAC increased the telomerase activity in folic acid deficient NSCs ( 0 $\mu \mathrm{M}$ folic acid, Table 1).

\section{(Insert Table 1 here).}

\section{Folic Acid Decreased Oxidative Damage and Increased Antioxidant Enzyme Activities}

Folic acid decreased ROS levels in NSCs in a dose-dependent manner ( $\mathrm{F}=170.325, p<0.001)$ (Figure 6). Similar effects of folic acid occurred when the medium contained $\mathrm{H}_{2} \mathrm{O}_{2}$ or NAC (Figure 6). $\mathrm{H}_{2} \mathrm{O}_{2}$ increased ROS levels across the range of folic acid doses $(F=3147.793, p<0.001)$, but NAC decreased ROS levels when folic acid lower than $10 \mu \mathrm{M}$ only $(\mathrm{F}=2163.538, p<0.001)$ (Figure 6a).

Folic acid deficiency increased medium LDH levels, intracellular LPO and MDA levels, indicating that oxidative damage occurred in those NSCs (Figure 6b-d). In contrast, folic acid supplementation dosedependently decreased medium LDH $(F=67.288, p<0.001)$, intracellular LPO $(F=80.331, p<0.001)$ and MDA $(F=61.352, p<0.001)$ (Figure 6b-d). Exogenous $\mathrm{H}_{2} \mathrm{O}_{2}$ increased medium LDH, intracellular $\mathrm{LPO}$ and MDA levels, whereas NAC decreased them (Figure 6b-d).

The effect of folic acid on improving antioxidant capacity in NSCs was evident in the data showing that the vitamin increased the levels of SOD, CAT, GSH-PX and the ratio of GSH/GSSG (all $p<0.001$ ) (Figure 6eh). Furthermore, $\mathrm{H}_{2} \mathrm{O}_{2}$ decreased antioxidant capacity in NSCs. NAC increased SOD and CAT levels at 10 and $20 \mu \mathrm{M}$ folic acid, and increased GSH-PX level only at $20 \mu \mathrm{M}$ folic acid (Figure $4 \mathrm{e}-\mathrm{h}$ ).

(Insert Figure 6 here).

\section{Discussion}

The results of the present study showed that folic acid deficiency in NSCs decreased intracellular folate concentration, cell proliferative capacity, telomere length and telomerase activity, but increased apoptosis, telomeric DNA oxidative damage and intracellular ROS levels. In contrast, folic acid supplementation dose-dependently increased intracellular folate concentration, cell proliferative capacity, telomere length and telomerase activity but decreased apoptosis, telomeric DNA oxidative damage and intracellular ROS levels. Exposure to $\mathrm{H}_{2} \mathrm{O}_{2}$ aggravated telomere attrition and oxidative damage whereas NAC alleviated the latter. High doses of folic acid prevented telomere attrition and telomeric DNA oxidative damage by $\mathrm{H}_{2} \mathrm{O}_{2}$.

Neurodegenerative diseases are characterized by a chronic and selective process of neuronal cell death. Folic acid is an essential nutrient that is vitally important to neural cell survival [14]. Folic acid deficiency has obvious impact on neural cell proliferation and could induce cell apoptosis [26]. In vitro studies have found that folic acid supplementation decreases apoptosis in astrocytes [8] and stimulates cell proliferation in embryonic NSCs [27]. In vivo studies have discovered that folic acid supplementation delays age-related neurodegeneration in the cerebral cortex and hippocampal CA1 region of senescence- 
accelerated mouse prone 8 (SAMP8) mice [17], whereas folic acid deficiency worsens neural cell injury in hippocampus following ischaemia/reperfusion injury [28]. Furthermore, in a recent study of Chinese patients with Parkinson's disease, relatively higher homocysteine and lower folate levels correlated with white matter hyperintensities [29]. The present study provided further insight by showing in primary NSCs that folic acid deficiency increased apoptosis and decreased cell proliferative capacity and whereas folic acid supplementation did the opposite.

Oxidative stress, resulting from an imbalance between ROS production and antioxidant defenses, contributes to aging and the pathogenesis of numerous diseases including neurodegenerative diseases [30-33]. SOD, CAT and GSH-PX are antioxidant enzymes that contribute importantly to cells' capacity for surviving oxidative stress [34,35]. The severity of oxidative stress in cultured cells can be assessed by measuring intracellular ROS, LPO and MDA, as well as by measuring the release of LDH from cells to the medium. In the present study, folic acid decreased medium LDH concentrations, lowered intracellular LPO and MDA levels, and increased the intracellular SOD, CAT, GSH-PX and T-AOC activities of NSCs. Taken together, these results indicated that sufficient amounts of folic acid could enhance antioxidant capacity and protected cells from oxidative damage.

Telomeres are dynamic nucleoprotein-DNA structures that cap and protect linear chromosome ends [36]. Critically short telomeres trigger cellular senescence in mature cells, which contributes to agingrelated degenerative diseases $[37,38]$. While numerous genetic and environmental factors are associated with telomere attrition, oxidative stress has been identified as an underlying mechanism [39]. Telomeric DNA is particularly vulnerable to oxidative damage because of its high level of guanine in the 5'-TTAGGG3 ' repeat sequence $[40,41]$. Guanine is the most susceptible of the natural bases to oxidation, commonly generating 8-OxoG, which is the most widely recognized biomarker for detecting oxidative damage in DNA $[42,43]$. A link between telomerase and oxidative stress is evident since it has been shown in human endothelial cells that chronic oxidative stress rapidly downregulates telomerase activity and accelerates telomere attrition [44].

Folate is essential for nucleotide synthesis and maintaining redox status [45]. A recent study showed that folic acid deficiency increases intracellular ROS levels, and aggravates telomere attrition in primary cultures of astrocytes [8]. There is evidence that a similar mechanism may occur in vivo since folic acid supplementation decreases ROS levels and alleviates both telomere attrition and telomeric DNA damage in SAMP8 mice [17]. The present study suggested that folic acid's actioned of suppressing ROS levels, telomere attrition and telomeric DNA oxidation, while increasing telomerase activity, might account for the vitamin's protection against NSC apoptosis.

Our previous study found that folic acid deficiency worsened neural cell injury in hippocampus following ischaemia/reperfusion injury [28]. Folic acid supplementation stimulates NSCs proliferation [12, 27] and neuronal differentiation [13]. We also found folic acid inhibited apoptosis in astrocytes in vitro and endothelial cells in vivo and in vitro. The protective effects may be due to folic acid decreased oxidative stress $[8,9]$. Moreover, Folic acid supplementation delayed age-related neurodegeneration and cognitive 
decline in SAMP8 mice, and alleviating telomere attrition could serve as one influential factor in the process [17]. For the depth of previous study, the effect of folic acid on apoptosis and telomeric attrition in primary NSCs were discussed in this study.

\section{Conclusion}

In conclusion, inhibition of oxidative damage-induced telomere attrition in NSCs may be a potential mechanism of inhibiting NSCs apoptosis by folic acid. The results suggested that folic acid supplementation might be a therapeutic strategy to people with neurodegenerative disease by preventing NSC apoptosis.

\section{Declarations}

Acknowledgements We thank Huan Liu, Bei Xu and Suhui Luo from National Demonstration Center for Experimental Preventive Medicine Education, Tianjin Medical University for their suggestions and technical assistance.

Author Contributions Z.L. and W.L. conducted data curation; Z.L. and W.L. wrote the original draft; Z.L. and D.Z. analyzed the data; J.Z., Y.M. and L.H. contributed methodology; C.D. contributed software; J.X.W. and G.H. reviewed and edited the draft; G.H. and W.L. contributed funding acquisition. All authors have read and agreed to the published version of the manuscript.

Funding This research was supported by a grant from the National Natural Science Foundation of China (No. 81730091), Natural Science Foundation of Tianjin (No. 19JCQNJC11700).

Data Availability All data generated or analyzed during this study are available from the corresponding author on reasonable request.

\section{Compliance with Ethical Standards}

Conflicts of interest The authors state that they have nothing to disclose and declare no conflict of interest.

Ethics Approval Not applicable to this study.

Consent to Participate Not applicable to this study.

Consent for Publication Not applicable to this study.

\section{Abbreviations}


CAT, catalase; DAPI, 4',6-diamidino-2-phenylindole; FPG, formamidopyrimidine DNA-glycosylase; GSH-PX, glutathione peroxidase; $\mathrm{GSSG}$, oxidized glutathione; $\mathrm{H}_{2} \mathrm{O}_{2}$, hydrogen peroxide; $\mathrm{LDH}$, lactate dehydrogenase; LPO, lipid peroxide; MDA , malondialdehyde; MTS, 3-(4,5-dimethylthiazol-2-yl)-5-(3carboxymethoxyphenyl)-2-(4-sulfophenyl)-2H-tetrazolium; 8-OxoG, 8-oxoguanine; PBS, phosphatebuffered saline; NAC, N-acetyl-L-cysteine; NSC, neural stem cell; ROS, reactive oxygen species; SAMP8, senescence-accelerated mouse prone 8; SOD, superoxide dismutase; T-AOC, total antioxidant capacity

\section{References}

1. Liu, Z., Zhou, T., Ziegler, A. C., Dimitrion, P., Zuo, L. (2017). Oxidative Stress in Neurodegenerative Diseases: From Molecular Mechanisms to Clinical Applications. Oxidative Medicine and Cellular Longevity, 2017, 1-11. doi:10.1155/2017/2525967

2. Kieroń, M., Żekanowski, C., Falk, A., Wężyk, M. (2019). Oxidative DNA Damage Signalling in Neural Stem Cells in Alzheimer's Disease. Oxidative Medicine and Cellular Longevity, 2019, 110. doi:10.1155/2019/2149812

3. Shoemaker LD, Kornblum HI. (2016). Neural Stem Cells (NSCs) and Proteomics. Molecular \& Cellular Proteomics, 15(2):344-54. doi: 10.1074/mcp.0115.052704

4. O'Sullivan, R. J., Karlseder, J. (2010). Telomeres: protecting chromosomes against genome instability. Nature Reviews Molecular Cell Biology, 11(3), 171-181. doi:10.1038/nrm2848

5. Shay, J. W., Wright, W. E. (2019). Telomeres and telomerase: three decades of progress. Nature Reviews Genetics. doi:10.1038/s41576-019-0099-1

6. Srinivas, N., Rachakonda, S., Kumar, R. (2020). Telomeres and Telomere Length: A General Overview. Cancers, 12(3), 558. doi:10.3390/cancers 12030558

7. Graf, M., Bonetti, D., Lockhart, A., Serhal, K., Kellner, V., Maicher, A., Jolivet, P., Teixeira, M. T., Luke, B. (2017). Telomere Length Determines TERRA and R-Loop Regulation through the Cell Cycle. Cell, 170(1), 72-85.e14. doi:10.1016/j.cell.2017.06.006

8. Li, W., Ma, Y., Li, Z., Lv, X., Wang, X., Zhou, D., Luo, S., Wilson, J. X., Huang, G. (2019). Folic Acid Decreases Astrocyte Apoptosis by Preventing Oxidative Stress-Induced Telomere Attrition. International Journal of Molecular Sciences, 21(1), 62. doi:10.3390/ijms21010062

9. Cui, S., Lv, X., Li, W., Li, Z., Liu, H., Gao, Y., Huang, G. (2018). Folic acid modulates VPO1 DNA methylation levels and alleviates oxidative stress-induced apoptosis in vivo and in vitro. Redox Biology, 19, 81-91. doi:10.1016/j.redox.2018.08.005

10. Barnes, R. P., Fouquerel, E., Opresko, P. L. (2018). The impact of oxidative DNA damage and stress on telomere homeostasis. Mechanisms of Ageing and Development. doi:10.1016/j.mad.2018.03.013 
11. Reynolds, E. (2006). Vitamin B12, folic acid, and the nervous system. The Lancet Neurology, 5(11), 949-960. doi:10.1016/s1474-4422(06)70598-1

12. Li, W., Yu, M., Luo, S., Liu, H., Gao, Y., Wilson, J. X., Huang, G. (2013). DNA methyltransferase mediates dose-dependent stimulation of neural stem cell proliferation by folate. The Journal of Nutritional Biochemistry, 24(7), 1295-1301. doi:10.1016/j.jnutbio.2012.11.001

13. Luo, S., Zhang, X., Yu, M., Yan, H., Liu, H., Wilson, J. X., Huang, G. (2013). Folic Acid Acts Through DNA Methyltransferases to Induce the Differentiation of Neural Stem Cells into Neurons. Cell Biochemistry and Biophysics, 66(3), 559-566. doi:10.1007/s12013-012-9503-6

14. Jia, D., Liu, H., Wang, F., Liu, S., Ling, E., Liu, K., Hao, A. (2008). Folic acid supplementation affects apoptosis and differentiation of embryonic neural stem cells exposed to high glucose. Neuroscience Letters, 440(1), 27-31. doi:10.1016/j.neulet.2008.05.053

15. Khandelwal, S., Boylan, M., Kirsch, G., Spallholz, J. E., Gollahon, L. S. (2020). Investigating the Potential of Conjugated Selenium Redox Folic Acid as a Treatment for Triple Negative Breast Cancer. Antioxidants, 9(2), 138. doi:10.3390/antiox9020138

16. Pang, Z., Zhou, J., Sun, C. (2020). Ditelluride-Bridged PEG-PCL Copolymer as Folic Acid-Targeted and Redox-Responsive Nanoparticles for Enhanced Cancer Therapy. Frontiers in Chemistry, 8. doi:10.3389/fchem.2020.00156

17. Lv, X., Wang, X., Wang, Y., Zhou, D., Li, W., Wilson J. X., Chang, H., Huang, G. (2019). Folic acid delays age-related cognitive decline in senescence-accelerated mouse prone 8: alleviating telomere attrition as a potential mechanism. Aging, 11(22):10356-10373. doi:10.18632/aging.102461

18. Jeesun Kim, Paul K.Y. Wong. (2009). Loss of ATM impairs proliferation of neural stem cells through oxidative stress-mediated p38 MAPK signaling. Stem Cells. 27(8):1987-98. doi: 10.1002/stem.125

19. Chien-Cheng Chen, Ching-Wu Hsia, Cheng-Wen Ho, Chang-Min Liang, Chieh-Min Chen, Kun-Lun Huang, Bor-Hwang Kang, Yi-Hui Chen. (2017). Hypoxia and hyperoxia differentially control proliferation of rat neural crest stem cells via distinct regulatory pathways of the HIF1a-CXCR4 and TP53-TPM1 proteins. Dev Dyn. 246(3):162-185. doi: 10.1002/dvdy.24481

20. Liu XL, Lu YS, Gao JY, Marshall C, Xiao M, Miao DS, Karaplis A, Goltzman D, Ding J. (2013). Calcium sensing receptor absence delays postnatal brain development via direct and indirect mechanisms. Mol Neurobiol, 48:590-600. doi: 10.1007/s12035-013-8448-0

21. Cawthon, R. M. (2009). Telomere length measurement by a novel monochrome multiplex quantitative PCR method. Nucleic Acids Research, 37(3), e21-e21. doi:10.1093/nar/gkn1027

22. Dong, Y., Zhang, G., Yuan, X., Zhang, Y., Hu, M. (2016). Telomere length and telomere repeating factors: Cellular markers for post-traumatic stress disorder-like model. Journal of Affective Disorders, 
195:156-162. doi: 10.1016/j.jad.2016.02.032

23. Mishra D, Rai R, Srivastav SK, Srivastav AK. (2011). Histological alterations in the prolactin cells of a teleost, Heteropneustes fossilis, after exposure to cypermethrin. Environ Toxicol. 26(4):359-363. doi: 10.1002/tox.20562

24. Canton CG, Anadon A, Meredith C. (2012). $\mathrm{Y}-\mathrm{H} 2 \mathrm{AX}$ as a novel endpoint to detect DNA damage: applications for the assessment of the in vitro genotoxicity of cigarette smoke. Toxicol In Vitro. 26(7):1075-1086. doi: 10.1016/j.tiv.2012.06.006

25. O'Callaghan, N., Baack, N., Sharif, R., Fenech, M. (2011). A qPCR-based assay to quantify oxidized guanine and other FPG-sensitive base lesions within telomeric DNA. BioTechniques, 51(6). doi:10.2144/000113788

26. Louisa S Tang, Daniel R Santillano, Bogdan J Wlodarczyk, Rajesh C Miranda, Richard H Finnell. (2005). Role of Folbp1 in the regional regulation of apoptosis and cell proliferation in the developing neural tube and craniofacies. 15;135C(1):48-58. Am J Med Genet C Semin Med Genet. doi:

10.1002/ajmg.c.30053

27. Liu, H., Huang, G., Zhang, X., Ren, D., Wilson, J. X. (2010). Folic Acid Supplementation Stimulates Notch Signaling and Cell Proliferation in Embryonic Neural Stem Cells. Journal of Clinical Biochemistry and Nutrition, 47(2), 174-180. doi:10.3164/jcbn.10-47

28. Cheng, M., Yang, L., Dong, Z., Wang, M., Sun, Y., Liu, H., Wang, X., Sai, N., Huang, G., Zhang, X. (2019). Folic acid deficiency enhanced microglial immune response via the Notch1/nuclear factor kappa B p65 pathway in hippocampus following rat brain I/R injury and BV2 cells. Journal of Cellular and Molecular Medicine. doi:10.1111/jcmm.14368

29. Shen, Y., Dong, Z., Pan, P., Xu, G., Huang, J, Liu, C. (2019). Association of homocysteine, folate, and white matter hyperintensities in Parkinson's patients with different motor phenotypes. Neurological Sciences. doi:10.1007/s10072-019-03906-3

30. Coray, T. W. (2016). Ageing, neurodegeneration and brain rejuvenation. Nature, 539(7628), 180-186. doi:10.1038/nature20411

31. Violi, F., Loffredo, L., Carnevale, R., Pignatelli, P., Pastori, D. (2017). Atherothrombosis and Oxidative Stress: Mechanisms and Management in Elderly. Antioxidants \& Redox Signaling, 27(14), 10831124. doi:10.1089/ars.2016.6963

32. Kahya, M. C., Nazıroğlu, M., Övey, İ. S. (2016). Modulation of Diabetes-Induced Oxidative Stress, Apoptosis, and Ca2+ Entry Through TRPM2 and TRPV1 Channels in Dorsal Root Ganglion and Hippocampus of Diabetic Rats by Melatonin and Selenium. Molecular Neurobiology, 54(3), 23452360. doi:10.1007/s12035-016-9727-3 
33. Hussain, T., Tan, B., Yin, Y., Blachier, F., Tossou, M. C. B., Rahu, N. (2016). Oxidative Stress and Inflammation: What Polyphenols Can Do for Us? Oxidative Medicine and Cellular Longevity, 2016, 1-9. doi:10.1155/2016/7432797

34. Liu, Z., Nie, R., Liu, Y., Li, Z., Yang, C., Xiong, Z. (2017). Effects of total soy saponins on free radicals in the quadriceps femoris, serum testosterone, LDH, and BUN of exhausted rats. Journal of Sport and Health Science, 6(3), 359-364. doi:10.1016/j.jshs.2016.01.016

35. Moretti, E., Micheli, L., Noto, D., Fiaschi, A. I., Menchiari, A., Cerretani, D. (2019). Resistin in Human Seminal Plasma: Relationship with Lipid Peroxidation, CAT Activity, GSH/GSSG Ratio, and Semen Parameters. Oxidative Medicine and Cellular Longevity, 2019, 1-8. doi:10.1155/2019/2192093

36. Shay, J. W. (2018). Telomeres and aging. Current Opinion in Cell Biology, 52, 17. doi:10.1016/j.ceb.2017.12.001

37. Rivera, T., Haggblom, C., Cosconati, S., Karlseder, J. (2016). A balance between elongation and trimming regulates telomere stability in stem cells. Nature Structural \& Molecular Biology, 24(1), 3039. doi:10.1038/nsmb.3335

38. Liu, J., Wang, L., Wang, Z., Liu, J. (2019). Roles of Telomere Biology in Cell Senescence, Replicative and Chronological Ageing. Cells, 8(1), 54. doi:10.3390/cells8010054

39. Sousounis, K., Baddour, J. A., Tsonis, P. A. (2014). Aging and Regeneration in Vertebrates. Current Topics in Developmental Biology, 217-246. doi:10.1016/b978-0-12-391498-9.00008-5

40. Aeby, E., Ahmed, W., Redon, S., Simanis, V., Lingner, J. (2016). Peroxiredoxin 1 Protects Telomeres from Oxidative Damage and Preserves Telomeric DNA for Extension by Telomerase. Cell Reports, 17(12), 3107-3114. doi:10.1016/j.celrep.2016.11.071

41. Von Zglinicki, T., Pilger, R., Sitte, N. (2000). Accumulation of single-strand breaks is the major cause of telomere shortening in human fibroblasts. Free Radical Biology and Medicine, 28(1), 64-74. doi:10.1016/s0891-5849(99)00207-5

42. Aeby, E., Ahmed, W., Redon, S., Simanis, V., Lingner, J. (2016). Peroxiredoxin 1 Protects Telomeres from Oxidative Damage and Preserves Telomeric DNA for Extension by Telomerase. Cell Reports, 17(12), 3107-3114. doi:10.1016/j.celrep.2016.11.071

43. Chernikov, A. V., Gudkov, S. V., Usacheva, A. M., Bruskov, V. I. (2017). Exogenous 8-oxo-7,8-dihydro-2'deoxyguanosine: Biomedical properties, mechanisms of action, and therapeutic potential. Biochemistry (Moscow), 82(13), 1686-1701. doi:10.1134/s0006297917130089

44. Kurz, D. J. (2004). Chronic oxidative stress compromises telomere integrity and accelerates the onset of senescence in human endothelial cells. Journal of Cell Science, 117(11), 24172426. doi:10.1242/jcs.01097 
45. Gorelova, V., De Lepeleire, J., Van Daele, J., Pluim, D., Meï, C., Cuypers, A., Leroux, O., Rébeillé, F., H M Schellens, J., Blancquaert, D., P Stove, S., Van Der Straeten, D. (2017). Dihydrofolate Reductase/Thymidylate Synthase Fine-Tunes the Folate Status and Controls Redox Homeostasis in Plants. The Plant Cell, 29(11), 2831-2853. doi:10.1105/tpc.17.00433

\section{Tables}

Table 1. Telomerase activity in NSCs

\begin{tabular}{|c|c|c|c|c|c|}
\hline $\mathrm{FA} \otimes \mu \mathrm{M} \nabla$ & $\begin{array}{l}\mathrm{H}_{2} \mathrm{O}_{2} \\
(\mathbb{\nabla} /-)\end{array}$ & 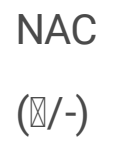 & $\begin{array}{l}\text { Cq } \\
(\text { Mean } \pm \text { SEM) }\end{array}$ & $\begin{array}{l}\Delta \mathrm{Cq} \\
(\text { Mean } \pm \mathrm{SEM})\end{array}$ & $\begin{array}{l}\text { Activity hTERT } \\
\text { (Mean } \pm \text { SEM) }\end{array}$ \\
\hline \multirow[t]{3}{*}{0} & - & - & \33 & - & No Activity* \\
\hline & $\square$ & - & ष33 & - & No Activity ${ }^{*}$ \\
\hline & - & प & $31.74 \pm 0.32$ & $1.91 \pm 0.28$ & $0.29 \pm 0.06$ \\
\hline \multirow[t]{3}{*}{10} & - & - & $29.83 \pm 0.54$ & 0.00 & 1.00 (Ref) \\
\hline & 口 & - & $\bigotimes 33$ & - & No Activity* \\
\hline & - & प & $29.43 \pm 0.28$ & $-0.40 \pm 0.28$ & $1.75 \pm 0.21$ \\
\hline \multirow[t]{3}{*}{20} & - & - & $29.64 \pm 0.45$ & $-0.19 \pm 0.22$ & $1.47 \pm 0.23$ \\
\hline & प & - & $29.89 \pm 0.85$ & $0.06 \pm 0.40$ & $1.32 \pm 0.40$ \\
\hline & - & प & $29.07 \pm 0.52$ & $-0.76 \pm 0.44$ & $1.93 \pm 0.50$ \\
\hline \multirow[t]{3}{*}{40} & - & - & $29.16 \pm 0.13$ & $-0.67 \pm 0.61$ & $2.04 \pm 0.84$ \\
\hline & प & - & $29.91 \pm 0.67$ & $0.08 \pm 0.40$ & $1.51 \pm 0.92$ \\
\hline & - & ૫ & $28.91 \pm 0.34$ & $-0.92 \pm 0.24$ & $2.26 \pm 0.17$ \\
\hline
\end{tabular}

$\Delta C q$ is quantification cycle value obtained from qPCR assay.

*, In accordance with the kit manufacturer's instructions, telomerase activity was recorded as no telomerase activity (i.e. activity too low to detect) if the Cq-value was higher than 33 . 


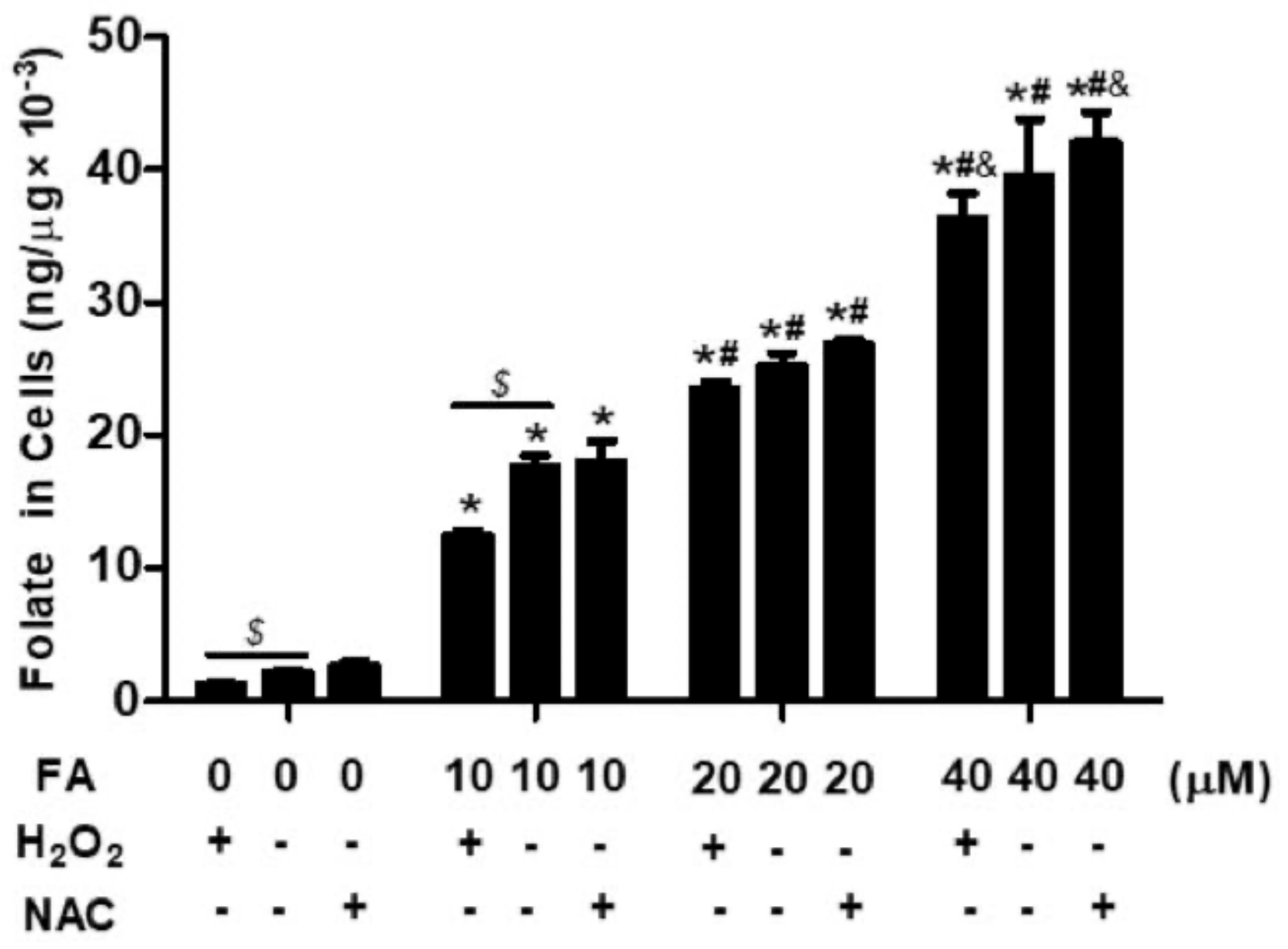

Figure 1

Intracellular folate concentration. NSCs were incubated for 9 days with various concentrations of folic acid $(0-40 \mu \mathrm{M})$, and then incubated for $24 \mathrm{~h}$ with a combination of folic acid and either H2O2 $(100 \mu \mathrm{M})$ or NAC $(10 \mathrm{mM})$ or vehicle. The plotted values represent the mean \pm SEM values of three independent experiments. Statistical analysis was performed using two-way ANOVA. *, $p<0.05$ compared with $0 \mu \mathrm{M}$ folic acid (FA). \#, p<0.05 compared with $10 \mu \mathrm{M}$ folic acid. \&, $\mathrm{p}<0.05$ compared with $20 \mu \mathrm{M}$ folic acid. \$, $\mathrm{p}<0.05$ compared with the group without $\mathrm{H} 2 \mathrm{O} 2$ or NAC at the same folic acid level. 


\section{a}

FA $0 \mu \mathrm{M}$

Fluorescein-

12-dUTP

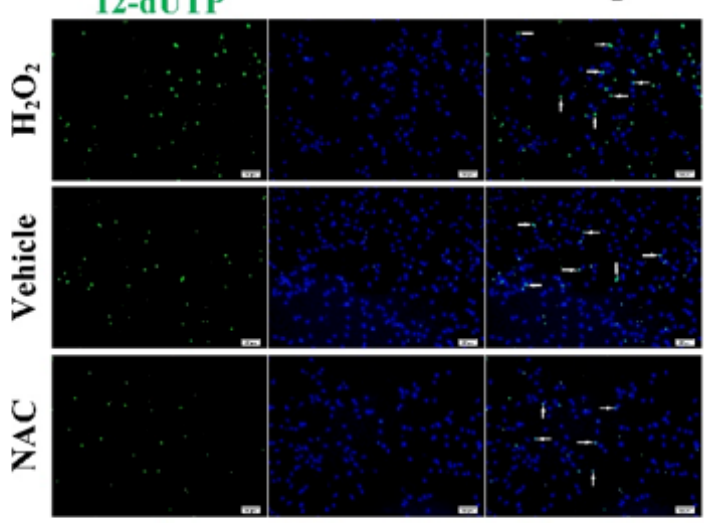

C FA $20 \mu \mathrm{M}$

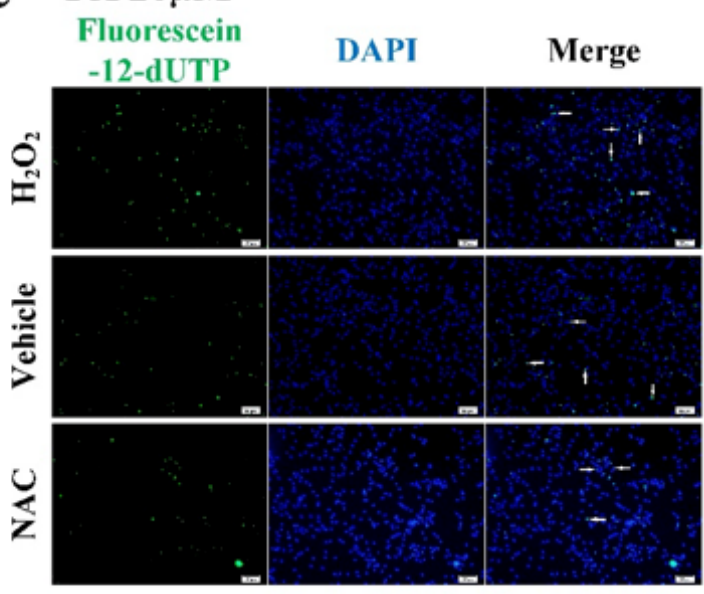

b FA $10 \mu \mathrm{M}$

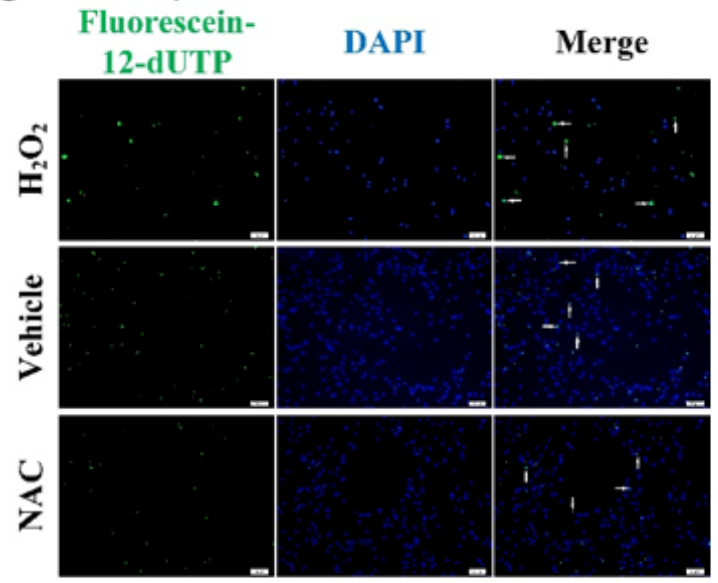

d $\mathbf{F A} 40 \mu \mathrm{M}$

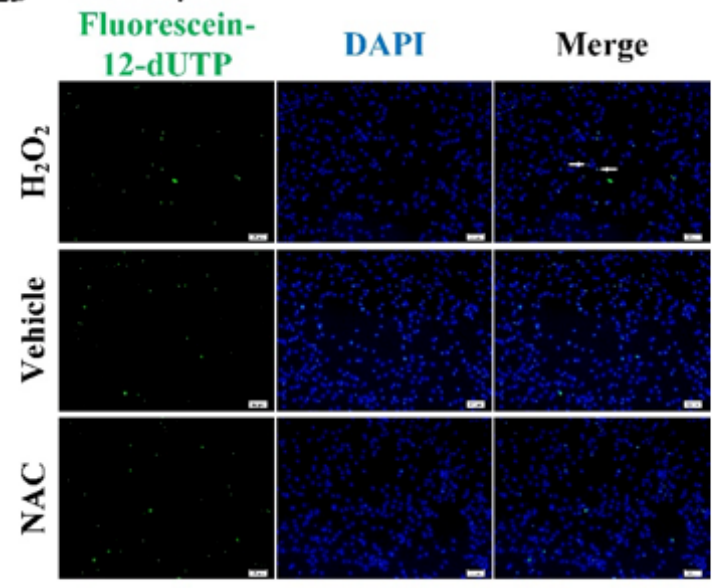

e

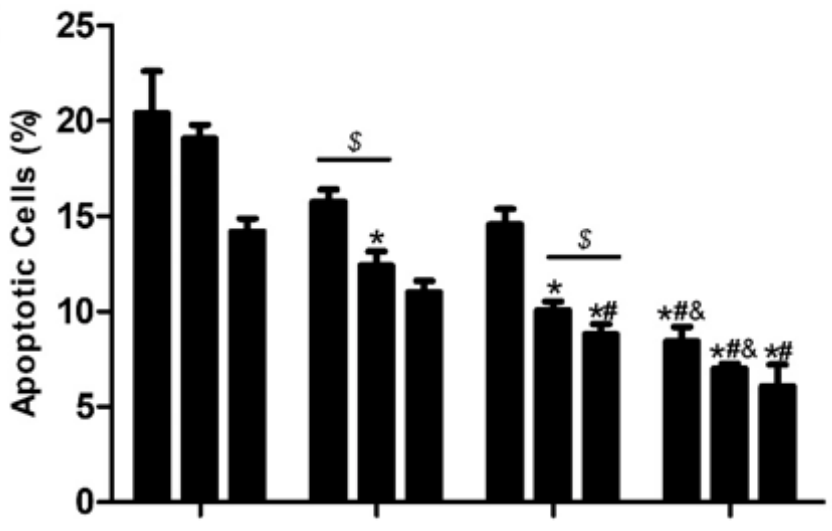

FA $\quad 0 \quad 0 \quad 0 \quad 101010 \quad 202020 \quad 404040 \quad(\mu \mathrm{M})$

$\mathrm{H}_{2} \mathrm{O}_{2}+--++-+-+_{-}+-$

NAC $--\quad+\quad-\quad+\quad+\quad-\quad+\quad-\quad+$

\section{Figure 2}

Cell apoptosis rates. NSCs were assessed to treatment groups as described in Figure 1, but were in adherence to a laminin substrate. (a-d) Cell apoptosis detected by TUNEL assay. Representative images of NSCs were stained with markers of fluorescein-12-dUTP (green), cell nuclei were stained with DAPI (blue), Double staining for fluorescein-12-dUTP and DAPI were indicated with arrows, the scale bar is 50 $\mu \mathrm{m}$. (e) Quantification of apoptotic-positive cells/total number of DAPI-stained nuclei. The plotted values 
represent the mean \pm SEM values of three independent experiments. Statistical analysis was performed using two-way ANOVA. *, $p<0.05$ compared with $0 \mu \mathrm{M}$ folic acid. \#, $\mathrm{p}<0.05$ compared with $10 \mu \mathrm{M}$ folic acid. \&, $\mathrm{p}<0.05$ compared with $20 \mu \mathrm{M}$ folic acid. \$, $\mathrm{p}<0.05$ compared with the group without $\mathrm{H} 2 \mathrm{O} 2$ or NAC at the same folic acid level.
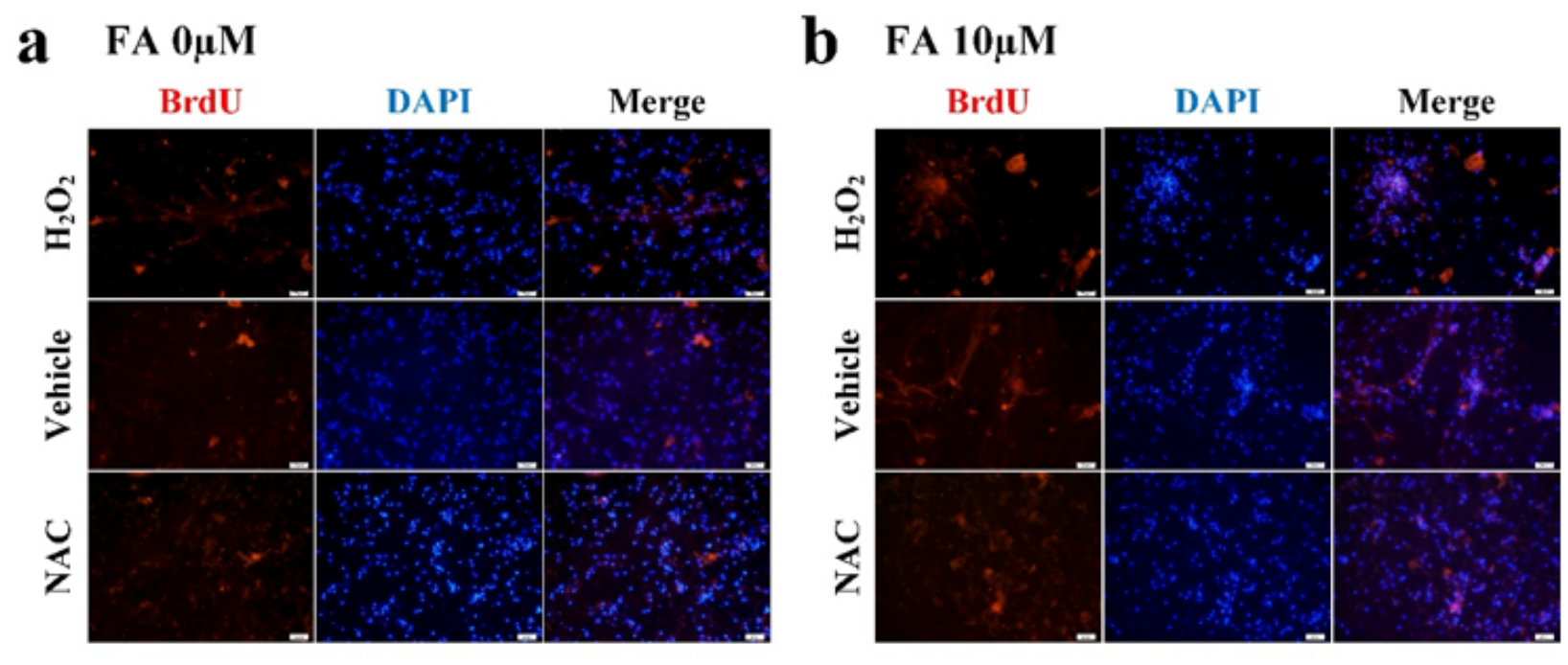

C FA $20 \mu \mathrm{M}$

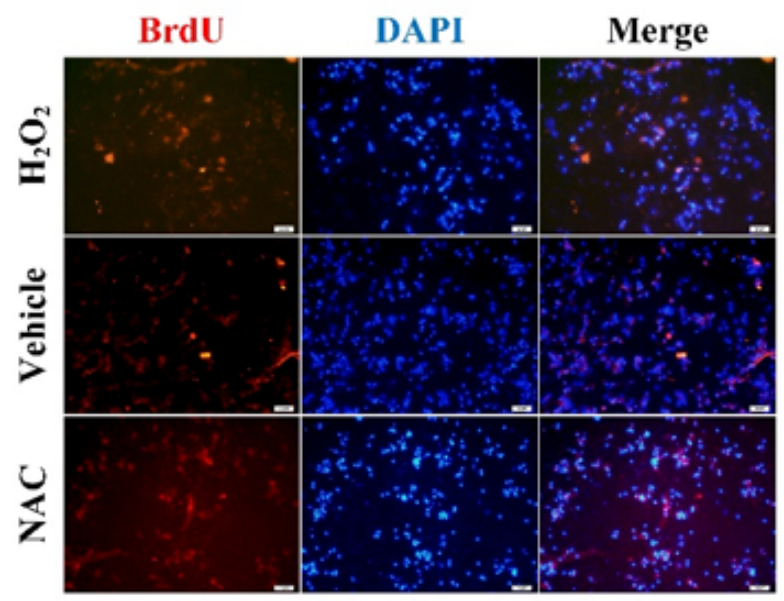

e

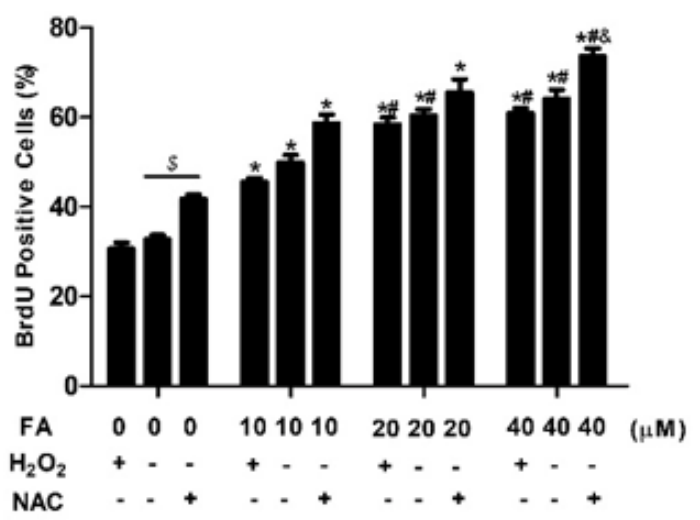

\section{d FA 40 $\mu \mathrm{M}$}

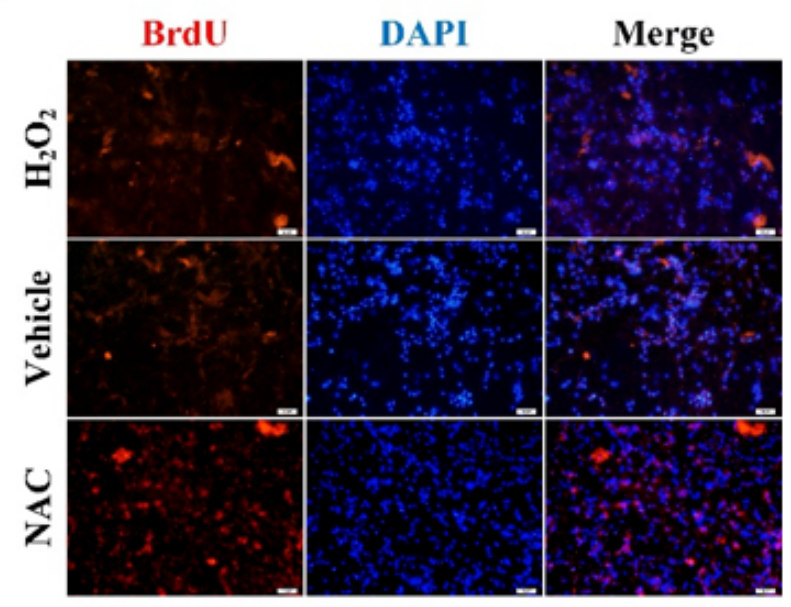

f

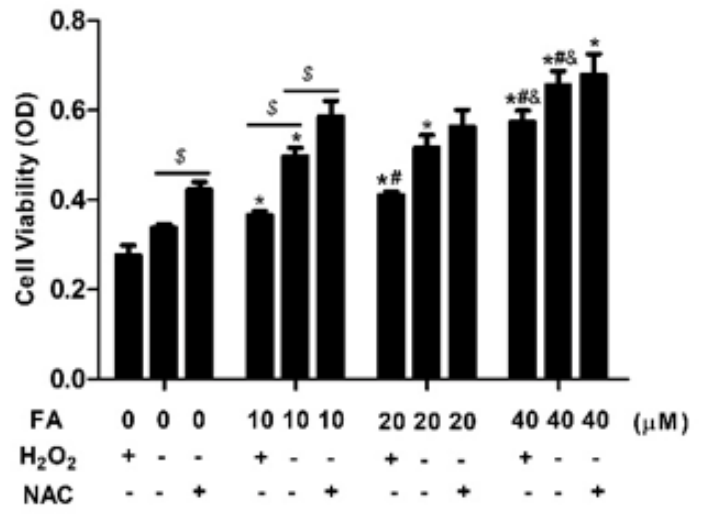

Figure 3 
Cell proliferative capacity and cell viability. NSCs were incubated as described in Figure 1. (a-d) Representative micrographs of the BrdU incorporation assay. Representative images of NSCs were stained with markers of BrdU (red), cell nuclei were stained with DAPI (blue), the scale bar is $50 \mu \mathrm{m}$. (e) Quantification of BrdU-positive cells/total number of DAPI-stained nuclei. (f) Cell viability detected by MTS assay. The plotted values represent the mean \pm SEM values of three independent experiments. Statistical analysis was performed using two-way ANOVA. *, $p<0.05$ compared with $0 \mu \mathrm{M}$ folic acid. \#, $\mathrm{p}<0.05$ compared with $10 \mu \mathrm{M}$ folic acid. \&, $\mathrm{p}<0.05$ compared with $20 \mu \mathrm{M}$ folic acid. $\$, \mathrm{p}<0.05$ compared with the group without $\mathrm{H} 2 \mathrm{O} 2$ or NAC at the same folic acid level.

a

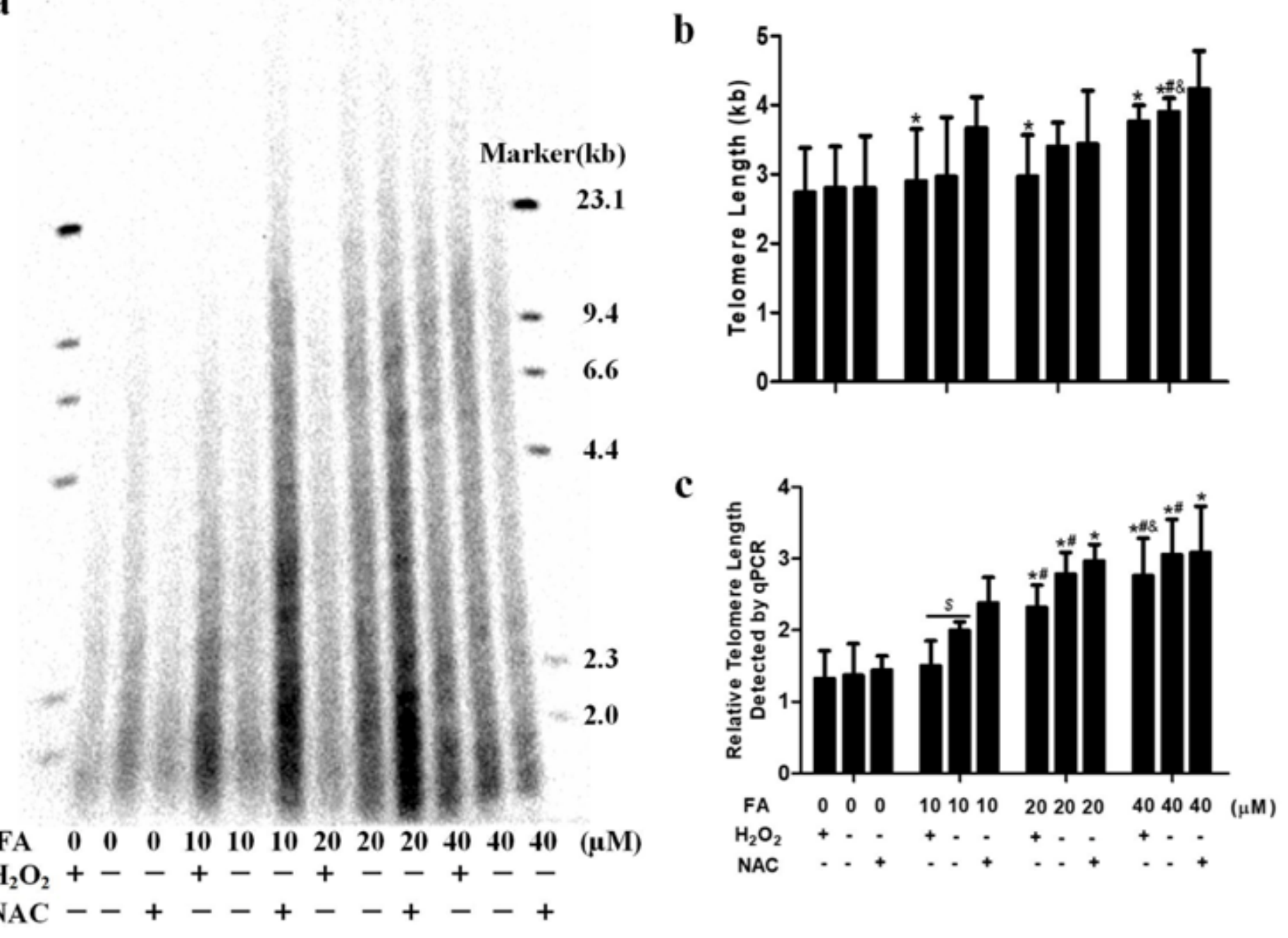

Figure 4

Telomere length of cells. NSCs were incubated as described in Figure 1. (a) Mean TRF detected by southern blot analysis. (b) Southern blot densitometric analysis of mean TRF for genomic DNA. (c) Relative telomere length of each group detected by q-PCR. The plotted values represent the mean \pm SEM values of three independent experiments. Statistical analysis was performed using two-way ANOVA. *, 
p<0.05 compared with $0 \mu \mathrm{M}$ folic acid. \#, $\mathrm{p}<0.05$ compared with $10 \mu \mathrm{M}$ folic acid. \&, $\mathrm{p}<0.05$ compared with $20 \mu \mathrm{M}$ folic acid. \$, p<0.05 compared with the group without $\mathrm{H} 2 \mathrm{O} 2$ or NAC at the same folic acid level.
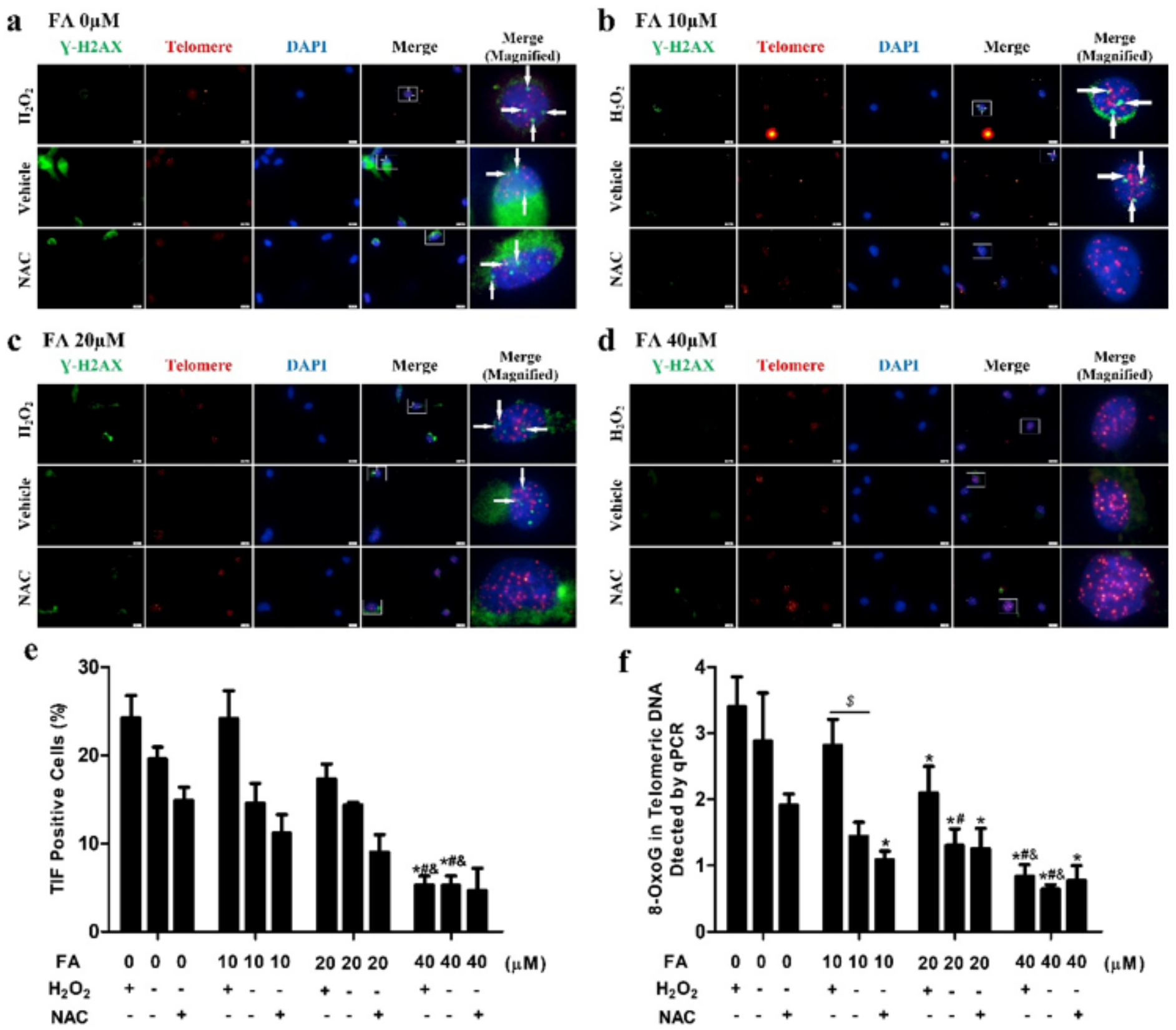

\section{Figure 5}

Telomeric DNA oxidative damage of cells. NSCs used into qPCR were incubated as described in Figure 1 and cells used into IF-FISH were in adherence to a laminin substrate. (a) Representative images of telomere IF-FISH (red, telomeric probe; green, \-H2AX probe; blue, DAPI-stained nuclei). Scale bar=10 $\mu \mathrm{m}$. (b) Percentages of TIF cells (containing both TelC-FITC and $\mathrm{B}-\mathrm{H} 2 \mathrm{AX}$ ). (c) 8-OHdG incorporation into telomeric DNA quantified by qPCR. The plotted values represent the mean \pm SEM values of three independent experiments. Statistical analysis was performed using two-way ANOVA. *, p<0.05 compared 
with $0 \mu \mathrm{M}$ folic acid. \#, $\mathrm{p}<0.05$ compared with $10 \mu \mathrm{M}$ folic acid. \&, $\mathrm{p}<0.05$ compared with $20 \mu \mathrm{M}$ folic acid. \$, $\mathrm{p}<0.05$ compared with the group without $\mathrm{H} 2 \mathrm{O} 2$ or NAC at the same folic acid level.

$\mathbf{a}$

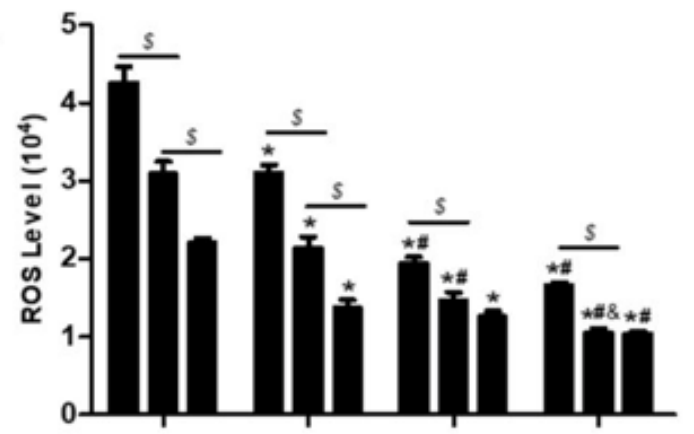

C

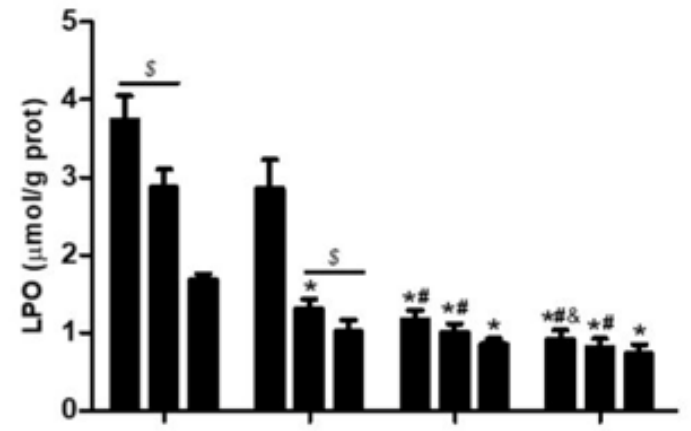

$\mathbf{e}$
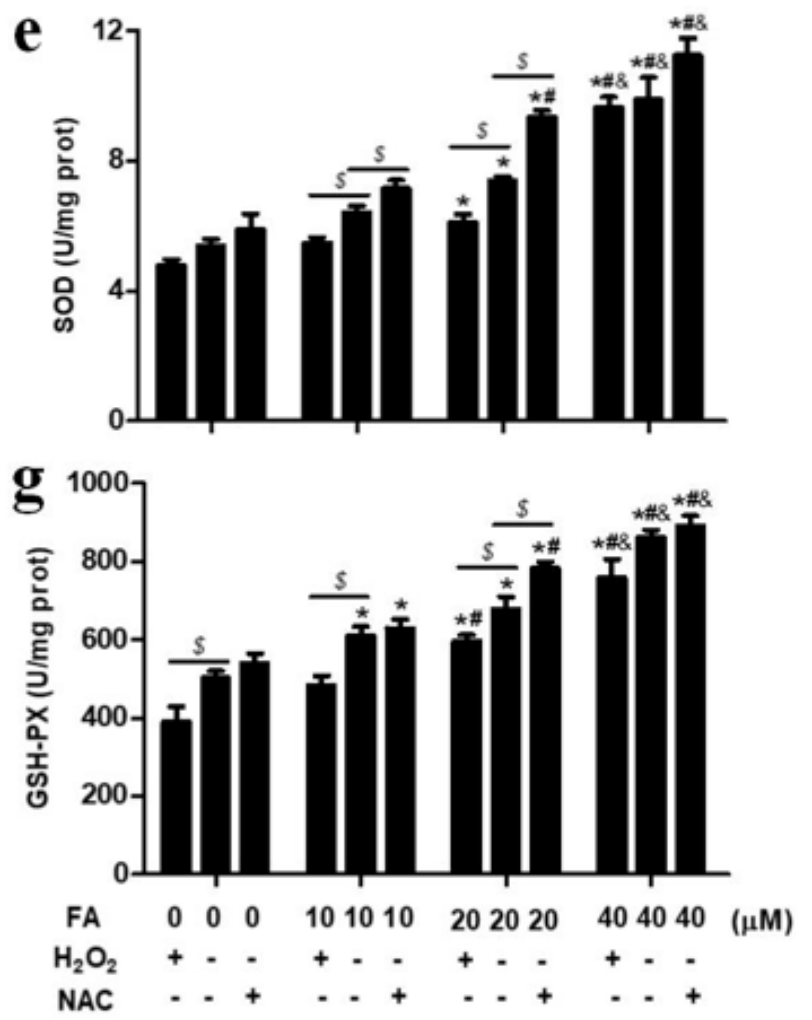

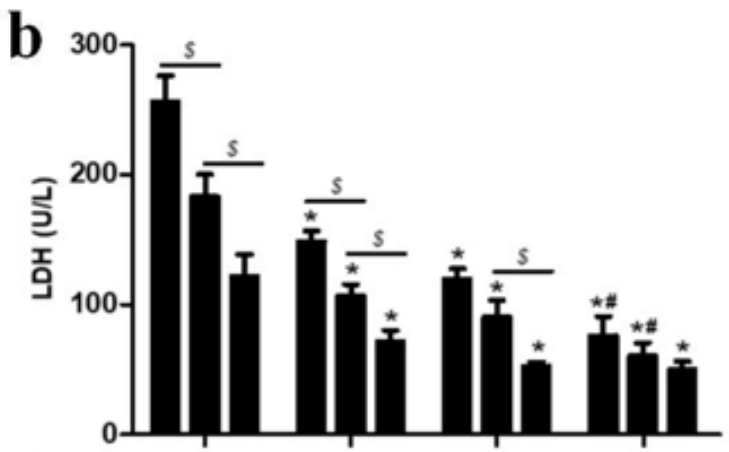

d
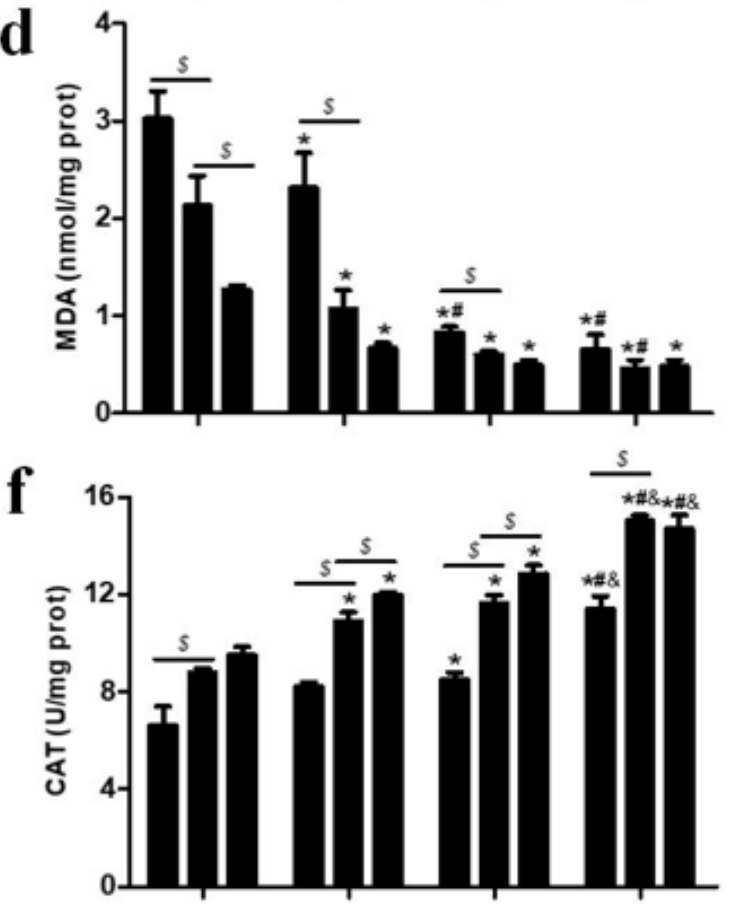

h

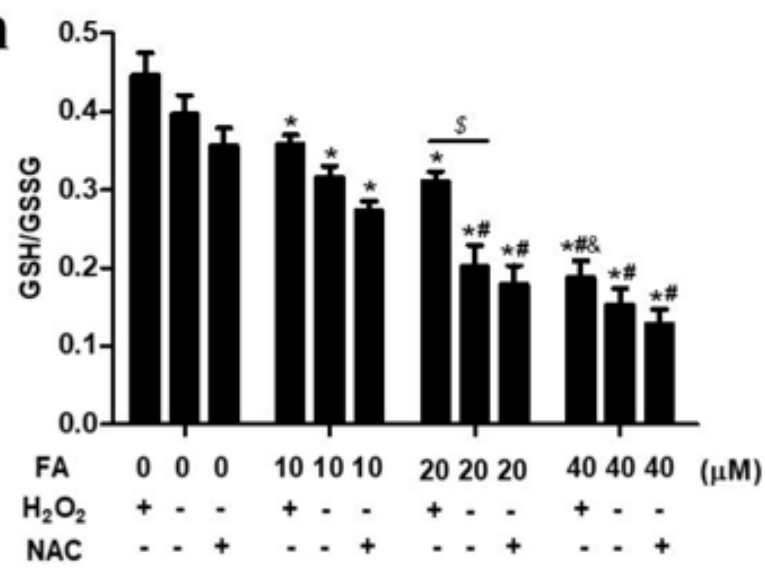

Figure 6

Oxidative injury and antioxidant activities. NSCs were incubated as described in Figure 1. (a) Intracellular ROS levels. (b) LDH levels in the culture medium after incubation with NSCs. (c) Intracellular LPO levels. (d) Intracellular MDA levels. (e) Intracellular SOD activities. (f) Intracellular CAT activities. (g) Intracellular 
GSH-PX activities. (h) Intracellular GSH/GSSG ratios. The plotted values represent the mean \pm SEM values of three independent experiments. Statistical analysis was performed using two-way ANOVA. *, $\mathrm{p}<0.05$ compared with $0 \mu \mathrm{M}$ folic acid. \#, $\mathrm{p}<0.05$ compared with $10 \mu \mathrm{M}$ folic acid. \&, $\mathrm{p}<0.05$ compared with $20 \mu \mathrm{M}$ folic acid. \$, $\mathrm{p}<0.05$ compared with the group without $\mathrm{H} 2 \mathrm{O} 2$ or NAC at the same folic acid level.

\section{Supplementary Files}

This is a list of supplementary files associated with this preprint. Click to download.

- Supplementaryfigure12021731.docx 